\title{
The Role Of The New Educational And Methodological Complex In The Development Of Intercultural Communication In Teaching Uzbek And Kyrgyz As A Foreign Language (Example of studying Uzbek and Kyrgyz as a second foreign language)
}

Karaeva Begam Kholmanovna, Candidate of Pedagogical Sciences, Moskovskiy Gosudarstvenniy Ling.univers. e-mail: karaeva_61@mail.ru

Khulkhachieva Zhenishkul Samatovna in Philology, Associate Professor, Head, Department languages and cultures of the CIS countries and neighboring countries MSLU. Email: j.khulkhachieva@linguagner.ru

\begin{abstract}
The article prevues the subjects of teaching students to speak in the process of studying the Uzbek language , Kyrgyz language as a second foreign language. The scientific and methodological literature and work programs for teaching types of speech activity, including oral , practical exercises, anthology, speech are analyzed. The problems of teaching students to monologic and dialogical speech are analyzed in detail. Methodical recommendations are given for practical application.
\end{abstract}

Keywords:

Studying process, Uzbek language, Krgyz second foreign language, types of speech activity, oral speech, monologue speech, dialogic speech, types of exercises, practical exercises anthology.

Article Received: 18 October 2020, Revised: 3 November 2020, Accepted: 24 December 2020

Today, in an era of globalization and integration between countries, the role of foreign languages as a means of communication requires a perfect mastery of the types of speech activities. Listening, reading, speaking and writing in a foreign language facilitate communication between members of society. increases.

Therefore, there is a need to fully master foreign languages among the members of the society and make perfect learning of foreign languages one of the topical issues on the agenda. Language learners' proficiency in foreign languages is tested by the extent to which they communicate in a foreign language and use the types of speech activities during communication.

Being able to express one's opinion freely in the process of oral and written communication shows how much each expert is aware of the activities of literature and media in their field. It is also very important for today's specialist to be able to express their opinion orally and in writing on the literature and articles read in a foreign language, to express their opinions, to be well acquainted with working papers.

Future professionals may have sufficient vocabulary in the reading process, master grammar rules well, pass exams and tests well, but communicating quickly in a foreign language can be difficult for them. All types of speech activities are closely related to each other. Comprehension through listening, comprehension of the content of the text through reading, communication through speech and expression of opinion, communication through writing and expression of own opinions are carried out.

Theoretical and practical aspects of teaching speech, one of the most important types of speech activity in the process of learning a foreign language, types of speech, lexical, phonetic, grammatical and stylistic aspects of speech have been studied in detail by many Russian and Uzbek scholars. 
B.A. Lapidus emphasizes that in order to ensure the effectiveness of teaching speech, it is necessary to sufficiently clarify the purpose and content of teaching this type of speech activity. In the process of learning a second foreign language, it is necessary to ensure the simultaneous learning of monologue and dialogic speech, what methods can be used in teaching methods to achieve this? In solving the problems of teaching these two types of speech, it is necessary to pay attention not only to their specific aspects, but also to their unifying aspects, mechanisms of sentence construction, sequence of sentences, equal use of sentences, as well as stylistic point of view of the author's language material. from the point of view suggests that teaching to speak a second foreign language should be focused on a neutral style, which does not preclude the use of high-level biblical words in monologues and dialogues. [4,62-63b] The system of exercises for teaching speech in the sources of foreign language teaching methods of the twentieth century is divided into two groups, which are traditionally divided into language training and speech exercises. As in all areas of science, changes and developments in foreign language teaching methods continue. Therefore, a system of exercises for teaching speech, an in-depth study of the mechanisms of speech requires the development of a multi-stage exercise system from this system of exercises.

In the literature on foreign language teaching methods of the twentieth century, the system of exercises for teaching speech is mainly divided into two groups. The first group includes language training exercises, and the second group includes speech exercises. Such an exercise system can still be used today. If we analyze the speech mechanism and its components in sequence, it will be easier to teach different types of speech activities, including speech, using a system of multi-step exercises in today's methodology.

I.V. Rakhmanov's textbook "Osnovnye napravleniya $\mathrm{V}$ metodike prepodavaniya inostrannogo yazyka" says that the three-stage system of exercises is very suitable for teaching types of speech activities. These methods are receptive, reproductive, and productive exercise systems. The same goal is pursued by the complex of design tasks. For example, students are invited, using the materials of a certain module and additional sources of their choice, to prepare a presentation in the Kyrgyz language on one of the following topics: a) The problem of selfidentification of the people in the modern world (for example, Kyrgyzstan); b) Problems and life of modern national diasporas (Kyrgyz in Russia, Russian in Kyrgyzstan); c) The role of the principles of good neighborliness and mutual respect in the formation of interstate relations.

Speech is a verbal type of speech activity, so it is studied in a state that is inextricably linked with listening comprehension. Types of speech can include a monologue, a dialogue, or a dialogue between two interlocutors, as well as a conversation between several participants in the form of a polylogue. All three types of speech are performed in connection with hearing .

A monologue is a speech that focuses on one or more as well as a large number of listeners who are listening to the speaker. In the learning process, such a speech may include a teacher's speech, a student's extended response on a topic, information, or lectures. Monologic speech differs from dialogic speech in that it is structurally complex, because in a monologue speech the idea is expressed in a completed form, each sentence, sentence is told in sequence, following grammatical rules. The fact that the introductory, main part and concluding parts of a monologue speech are related to each other shows that it is more complex than a dialogic speech. Monologue speech cannot be mastered quickly. Monologic speech becomes more complex during the stages of language learning, from simple to complex, independent work monologue can be in several forms or in content. These include simple types of speech, such as giving simple information or data, describing an analysis, describing, describing, recommending a scene or portrait. Information can be given in different contexts, there are several ways of narration, and in the description there are many more possibilities, that is, it is possible to 
describe an event, an object, a landscape, a portrait. If we delve deeper into them, we can say that a single portrait is able to describe the general portrait, its exterior and interior, and to express its conclusions in a monologue. These types of monologues can be narrated both in writing and orally, but when analyzing foreign language teaching, we can focus on the oral speech form, as it is expedient to consider written speech teaching in the process of writing speech activities. It is obvious that all types of speech activities are interrelated processes. The monologue is often done in a well-planned, well-prepared manner.

IN Kuznetsov's oral monologue is one of the most important aspects of oral communication considers it a complex appearance. According to the author, monologue speech is about influencing people through language, with a specific purpose in mind. The purpose of narrating a monologue is primarily to inform the audience [3,122-123 p]. The appearance of a conversation or dialogue of speech activity is the communication of two interlocutors through language. In everyday conversations such preparation is not prepared in advance, the topic may change during such conversations, so such types of conversations cannot be planned in advance. In the process of learning a foreign language, the conversations given during the practical training on the types of speech activities are planned on specific topics. One of the studies conducted in recent years, I.A. Bredixina's research on teaching types of speech activities, analyzes the description of speech, speech teaching technology, exercises for oral communication, and pays special attention to monologue and dialogic aspects of speech. The external structure of speech by the author is divided into several parts.First, the motivational effect. It can be said that the need consists in the occurrence of the necessity, why it should be said, the influence and motivation of the interlocutor. The second is the emergence of the analytical-synthetic process. This process can be said to be the process by which speech emerges, the desire to express an idea is realized. Third, we can see the process of control. In this, dialogic and monologue views of speech are realized. The author divides the content of speech training into linguistic, psychological and methodological parts. The linguistic component of speech is the implementation of these language and speech units, this knowledge is studied on specific topics in the course of the training sessions. The psychological component is the ability to use emotion and color in speech. The methodological component of speech implies reliance, that is, the mastery of monologue speech in order to consciously carry out one's speech .

Another aspect of dialogic speech is that the conversation can take place face to face, over the phone, or using modern forms of communication. Differences in the level of knowledge, interests, and experiences of the interviewees affect the implementation, content, and quality of the interview.

For the V1 level in a foreign language, the following is required in the form of dialogue and monologue of speaking in the educational content:

1) Participate in conversations, interviews, verification and confirmation of information on the prepared topic; 2) Participate in a conversation on an unprepared topic (in our experience, when traveling to Uzbekistan); 3) Participate in a conversation in an unexpected situation; 4) Express their opinion on familiar topics (about books, movies, music); 5) Exchange of information on familiar and less familiar topics; 6) Participate in debates. Participate in debates.

In the form of a monologue, the language learner is required to: 1. Express his impressions, dreams and intentions; 2. Presentations on specialty topics; 3 . Be able to speak and explain their ideas and plans in the social and professional spheres; 4. Describe and narrate their impressions on the content of the book and film; 5. Narrate or summarize the content of the text under discussion in simple phrases.teachers can independently choose teaching methods, principles and teaching aids, take a creative approach to the implementation of the educational program. Of 
course, the existence of different approaches and methods of teaching a foreign language gives teachers the right to choose when conducting practical training. However, we can see that the use of teaching aids is much more popular, because language learners are more comfortable with individual-oriented competencies in terms of types of speech activities, especially in teaching speech. First, the organized environment allows students to feel free, stimulates their interest, there is a need for intensive learning of a foreign language and its application in practice, and their interest in language learning increases. The student approaches the learning process creatively, with great interest in independent work performs, becomes an active participant in the learning process, his ability to master speech is manifested in various forms.

The study of Uzbek as a second foreign language is mainly based on such subjects as "Uzbek as a second foreign language" in the 2nd, 3rd, 4th semesters and "Practice of the Uzbek language as a second foreign language" in the 5th, 6th, 7th and 8th semesters. The main role is played by the subject "Practice of the Uzbek language as a second foreign language", because during the study of this subject the student learns not only the ability to learn a foreign language, but also a lot of knowledge in the future profession. In addition, special subjects such as "Preparation for professional communication", "Professional communication-oriented translation" help students to further develop their speaking skills during language practice. These disciplines not only increase students' knowledge of listening comprehension, reading, speaking and writing in a foreign language, but also develop the student's worldview, quick thinking, and increase their potential [5].

Thus, in the current period of learning foreign languages, including speaking, communication activities are considered as teaching. Thus, the use of new innovative forms and methods of teaching communication activities will be implemented, which will increase the knowledge and skills of students in their fields and enrich the content, quality and effectiveness of learning a foreign language modern practice of creating textbooks of foreign languages, various approaches and criteria for achieving their effectiveness are used. The purpose of the publication, which will be discussed in this publication - "The Kyrgyz language for the CIS countries" [2], is to develop intercultural communicative competence among students, which will allow them to successfully communicate with native speakers of the target language, understand and accept culturally specific forms of behavior of representatives of another culture to achieve mutual understanding in the process of intercultural dialogue

Curricula use the following types of monologue to teach students learning Uzbek as a foreign language in a monologue: Greeting, selfintroduction, gratitude, apology, apology, congratulatory speech, praise, accusation or justification, speech, story, description, description , to react to an event, to express their opinions and conclusions, etc. The monologue, in turn, has certain descriptions, to which we can include: 1) the setting of a specific goal or purposefulness, depending on the function of the speech; sequence of ideas; logic; the completeness of the idea in terms of content; expressiveness. It is more difficult for a student learning Uzbek as a second foreign language to follow the above aspects of a monologue in the early stages of learning, but in the later stages of language learning he can apply these aspects of a monologue during his speech. A student's monologue is very different from a monologue. However, it can be said that the student's monologue in the course of the lesson is also done based on the speech situation. Of course, different situations arise in this process. Based on such situations, we recommend a number of situations in the textbook on the implementation of monologue speech. For example, on the basis of the proposed materials, the task is to prepare an advertising program for tourists from Russia under the proposal "Welcome" [1,244-245b].

First of all, the student must carefully study the given material, be able to identify the main 
content of the text and express his opinion on this basis. The student can first write such a text in his native language and translate it, and which words should be used during direct translation. tends to be engaging to the listener. When saying or performing a monologue, special attention is paid to the correct and beautiful pronunciation, logical emphasis, and conclusion of the thought. Such small monologues in the form of advertisements encourage creativity and further stimulate the student's interest in language learning. The assignments given to all members of the group may be similar, but they may differ in terms of word usage, sequence of ideas, arguments, and ideas they want to convey to the audience possible. We can call these monologues small monologues. After each student's individual speech is heard, the reaction is also expressed by the group members, who share their thoughts among the group members. The content and form of speech, ownership and agreement, and the correct or incorrect use of personal pronouns are analyzed.

Another such task is to verbally express a monologue in response to a text that has been read and the final questions are asked. According to the assignment on the text "Atlas of Margilan", students read a text about the Uzbek satin fabric and answer questions. The answers to the following questions constitute the student's monologue:

1. What kind of fabric is satin?

2. Where did satin weaving develop?

3. In what other cities of Uzbekistan is satin woven?

4. What is made of atlas?

5. What popular copies of the atlas are there?

6. Do people know satin fabric abroad?

7. Apart from satin, what other Uzbek national fabrics are there?

8. What fibers are these fabrics made of?

9. What else do you know about Atlas? [1, 256-257b].

This text is related to linguistics and is given in Uzbek. The text mentions the ancient cities of Uzbekistan, such as Margilan, Kokand, Namangan, Andijan and Samarkand. Students who prepare a monologue based on the text and questions on the text, of course, fill in their texts with additional sources, talking about the satin costumes of the heroes of the films they saw, artists, as well as express their views on the topic. This text is handed out on the basis of working on a monologue speech during the second phase of reading. In the later stages, the texts on the preparation of monologue speech become more complex, and in the final stages, more complex texts are worked on. Such complex texts are given in later stages. Such texts will be devoted to the history of Uzbekistan, cultural heritage, linguistics and geography, the chosen career of students. Texts are given in Uzbek and Russian, texts given in Uzbek are translated into Russian, texts given in Russian are translated into Uzbek, as well as several assignments on texts are given.

One of the texts on the preparation of a monologue on the topic of historical and cultural heritage of Uzbekistan contains the following tasks:

1. Get acquainted with the cultural heritage of Uzbekistan. Tell us about one of the examples of cultural heritage.

2. Which architectural monuments of Uzbekistan are included in the "List of World Spiritual Heritage"?

3. Comment on the photo attached to the article [2, 184-190b].

The text is in Russian, and the assignments are given in Uzbek, which are intended to be studied in later stages, complicated in terms of content and text structure, because the text is in Russian, students translate the text into Uzbek and only then start working on assignments.

Texts on socio-political issues in the curriculum for each semester will be interesting for students in terms of their chosen careers. UzbekRussian relations, cooperation between the two countries in political, socio-economic and cultural spheres, as well as regional issues the texts are structured in accordance with educational standards, both grammatically and in terms of content. The assignments given in these texts mainly include: 1 ) understanding the main content 
of the text; 2) Answering questions on the text; 3) Summarizing the content of the text; 4) Speaking the text on behalf of the first person or as a master speech; 5) Expressing their views on the text, expressing their attitude; 6) Write a short annotation to the text; 7) Continue the text or enrich it with evidence, additional information. During the performance of these tasks, the monologue of the demand becomes richer and more polished, which helps to achieve the goal of education. The student takes each text as a model and tries to think about similar topics, to participate in discussions. Such texts are the main source for the student's speech. According to such texts, which are studied in the later stages of language, the student's monologue can be based not on a single text, but on several texts or as a result of books read in the native language. Of course, a monologue is meaningful and logical only if it is carried out on a sequential basis. The student can also use the knowledge gained in other disciplines. It can be said that the expression of an idea, its implementation in the form of a monologue or dialogue, occurs as a pedagogical process, and we can divide it into several stages:

1. The process of choosing words, phrases on the topic;

2. Plan to summarize and present in sequence.

3. Keep in mind the grammatical rules when composing sentences, first of all pay attention to possessives, conjunctions, personal pronouns.

4. Expressing an opinion, expressing one's attitude.

Not only the lexical and grammatical material of the language is not enough to express an idea, make a monologue or participate in a dialogic speech, but also the extralinguistic means of the language, the tempo of speech, the ability to express message, message, command or interrogative content, slowing down, punctuation, language The use of gestures also plays an important role in fully conveying the idea to the interlocutor, the audience.

Thus, we can divide the exercises on monologue and dialogic speech in the process of practical training into two main groups. The first is a simple exercise performed on language material, i.e., an exercise for practice, in which, in terms of sentence construction, it is possible to continue these exercises by correctly construct ing and reading words, sentences, and phrases. This includes exercises on correcting mistakes in speech and sentence structure. This exercise can be repeated several times. Also, remembering and repeating what the student has said in his or her monologue in such exercises, or reciting it as a mastery speech, will further strengthen the mastery of these exercises. The second group of exercises is communication exercises. It is possible to perform exercises on the transmission of any information. It is also a good idea to start each lesson with news from around the world or from a specific country when dealing with students in the field of international relations and socio-politics. At the beginning of each lesson, the student has a growing desire to tell the news on this topic. The main content of this news will be news about the political, social and economic life in Uzbekistan and Russia, as well as news, changes and problems in the world. While in the early stages they performed small monologues made up of two or three sentences, in the later stages these novelties turn into larger texts, now in these texts the details are fully explained, the evidence is multiplied, summarized and the student's attitude is expressed. The conclusion is that the student's speaking skills do not develop on their own, it is necessary to continue such exercises and, if necessary, to increase the number of such exercises that form speech communication.

However, there are some difficulties in the process of preparing for a monologue and dialogic speech. First of all, insufficient understanding of the task given to communicate, insufficient knowledge of language and means of speech, and students' shyness, lack of self-confidence prevent them from developing speech in a foreign language, to quickly enter into oral communication. To do this, the environment created by the teacher, the conditions sufficient for free communication, lead students to actively participate in the lesson. 
In the textbook "Kyrgyz language for the CIS countries" the main content unit is texts as a means of implementing the set communicative tasks in teaching Russian-speaking students of linguistic universities with the level of knowledge of the Kyrgyz language and culture B1 / B2. The selection of text material was carried out on the basis of a set of criteria (substantive, linguistic, communicative), which made it possible to ensure its relevance, universality, informational content and accessibility. Possessing ethno cultural specifics, the test material gives students a complete picture of the linguistic picture of the world of the Kyrgyz linguistic personality.

"Mastering a language (regardless of whether it is a native or a foreign language) is not limited to memorizing language units and mastering the rules for combining them. This is only an elementary, "preparatory" level [5, p. 11], and then, as MM wrote. Bakhtin, "the individual speech experience of each person is formed and develops in continuous and constant interaction with other people's individual calls. This experience can be characterized as the process of mastering other people's words ". "Others' words", or their own, is a means of communication between communicants. As the famous linguist $\mathrm{H}$. Weinreich said: "Language is learned through texts".

The text as a unit of verbal communication and the main organizing link in the educational process provides students with knowledge about themselves and the world around them, expanding their abilities and ideas. At the same time, the text is not only an object of linguistic analysis, but also performs essential communicative functions, providing comprehensive training in all types of speech activity: listening, speaking, reading and writing.

"If the goal of training is the ability to communicate, then the text library should first of all illustrate the course of solving the communicative tasks of this course, motivate the setting of these tasks and contain subject regional material on which these tasks are set and solved" [3, p. 74].
Since in the textbook "Kyrgyz language for the CIS countries" the main content unit of teaching is texts, the identification of the main selection criteria and principles of their organization is of particular interest both for teachers and methodologists, and for the students themselves. In the textbook "Kyrgyz language for the CIS countries" the textbook is functionally conditioned: it is the source of the solution of the set communication tasks and contains speech and language material that creates conditions for their solution. It is the basis for constructing a formal speech minimum.

When creating the textbook under consideration, various extra linguistic factors were taken into account, including the learning conditions (linguistic university), the level of students' training (B1 / B2).

Since the textbook "Kyrgyz language for the CIS countries" is intended for persons who continue to study the language on the basis of the existing skills of receptive and productive types of speech activity in the Kyrgyz language, the selection of text material was organized in such a way as to provide interconnected training all types of speech activity. As studies show (Zimnyaya, Nemanova, Petropalova, 1986; Interconnected learning ..., 1985), the same psychophysiological mechanisms are involved in receptive and productive types of speech activity, among which the main one is comprehension. In addition, the mechanisms of perception and generation are largely the same, which ensures the mutual influence of different types of speech activity during interconnected learning, and as a result, the possibilities of controlled transfer of skills and abilities increase [6, p.168].

The implementation of these tasks, within the framework of the textbook "Kyrgyz language for the CIS countries", namely interconnected learning in receptive and productive types of speech activity, is reflected in the selection of posttext exercises and tasks. For example, "Listen to the text and define its theme; specify the following statements based on the information in the text; choose the correct meaning of the following 
phraseological units from the proposed options. Translate the following sentences, paying attention to the highlighted words and phrases. Compare the ways of expressing the same idea in the Kyrgyz and Russian languages. "

The development of speech skills within the framework of a single communicative competence is largely ensured in the course of performing tasks under the heading "Let's talk and discuss." For example, "Read the following statements about the relationship between cosmopolitanism and patriotism, the need to preserve the identity of the people. Express your opinion, justifying the choice of position. "

Students are also invited to comment on a number of statements in the Kyrgyz language, touching upon the most pressing problems and aspects of modern Kyrgyz society.

At the same time, the sources of culturological information include not only print and other media, but also live, direct communication with representatives of the Kyrgyz culture, including those living in Moscow and Russia as a whole. This approach promotes the development of independence and judgments and assessments in Russian-speaking students, and also provides natural conditions for the formation of their intercultural communicative competence.

When selecting textbook texts, adaptation is of particular importance. Adaptation is the simplification of the text, the reduction of elements of the plot-compositional structure, the selection and grouping of important and semantic fragments of the text, the reduction of methodically irrelevant vocabulary of the text, its replacement with the vocabulary known to students or the complication of the text according to the level of language training of students [4, p.14 ].

The degree of adaptation and the number of adapted texts is determined by the level of training of students and the goals and objectives of the training.

The textbook "Kyrgyz for the CIS countries" is intended for students with the level of knowledge of the Kyrgyz language and culture B1 / B2. In this regard, the share of non-adapted texts in it exceeds the share of adapted ones. It is the authentic unadapted texts that are of great pragmatic value, fully preserving the meaning of the message and the original means of its transmission. Being an integral part of the language culture of Kyrgyzstan, their reality, emotionality and originality increase the motivation of students. As noted above, the selection of texts took into account the level of students' communicativee (B1 / B2), which made it possible to avoid the negative impact on their motivation of both excessive language complexity and simplification of the material. At an advanced stage of learning, when students have a large active and passive vocabulary and can use the Kyrgyz language in various spheres of communicative communication, it is the unadapted texts that become the main object and means of teaching. However, in a number of cases, the authors of the textbook resorted to partial adaptation of educational texts: they were shortened in blocks with preservation of the content essence or highlighting the main content lines while making minimal changes to the microstructure without any significant change in the content plan.

The texts selected for the textbook under consideration meet the requirements of methodology and learning. Following A.R. Arutyunov, by methodicality we mean the adaptation of the text to the educational forms of work adopted in this training system (Arutyunov, 1990). Educational texts are the most effective in the process of teaching the Kyrgyz language. The following internal textual selection criteria played an important role in identifying the methodical character of the texts in the textbook "Kyrgyz language for the CIS countries": a) meaningful; b) communicative; c) linguistic.

Thus, the materials presented in the textbook of the textbook "The Kyrgyz Language for the CIS Countries" reflect social reality, offer students vital topics that are relevant to the Kyrgyz people for discussion, provide significant information of a cultural nature. The main substantive criteria for selecting texts for the textbook "Kyrgyz language for the CIS countries" were the following: 
1. Informativeness of the text. Providing information about facts, events, actions, in some cases containing the author's interpretation of the content.

2. Consistency and coherence of presentation. The materials presented in the textbook are arranged according to the principle from simple to complex, which ensures more effective assimilation of linguoculturological material.

3. The presence and nature of regional and linguistic-regional information, reflecting foreign language reality. In this textbook, the authors operate with such concepts as "concepts", "linguistic worldview", "linguistic thinking". At the same time, the subject of study and discussion is such concepts typical of Kyrgyz culture as "land of ancestors", "place", "sun", “friend", "neighbors", "venerable spirit", etc.

4. Reflection of the speech topic of the lesson, taking into account the thematic structure of the textbook. The communicative topics were not chosen by chance, they reflect the concepts that are key for the Kyrgyz linguistic picture of the world, and the preface in Russian preceding each module immediately introduces the student into the sociocultural context. For example, "The Kyrgyz language is a reflection of the history and culture of the people", "The Epos" Manas "is a monument of the culture of the people, the pinnacle of spirituality", "Traditions, customs and mentality of the Kyrgyz people", "Multinational Kyrgyzstan. Kyrgyz Diaspora in Foreign Countries ", "Modern Kyrgyzstan. Cities. Universities ".

In the textbook "Kyrgyz language for the CIS countries", the communicative criterion plays an important role in the selection of texts. The communicative text is understood by the authors as informative, cognitive and in line with the interests of a certain age and sociocultural group (in this case, students of a language university). At the advanced stage, it is especially important that the content of the text meets the intellectual and emotional needs of the students. The materials of the textbook in question fully comply with these requirements. So, in the topic "Multinational
Kyrgyzstan" there is an assignment to read the text and tell in the Kyrgyz language about the importance of international education, correct language policy and tolerance in relation to emerging interethnic problems. This text also tains key concepts such as "good neighborliness", "mutual understanding" and "mutual enrichment of languages and cultures", which requires deep familiarization with the traditions and customs of peoples. living in the neighborhood. Further, the topic of "self-identification of the people in the modern world" is developed and other related situations are discussed. So, the logical continuation of the work on the text is the task under the heading "Let's talk and discuss": Read the following statements about the relationship between cosmopolitanism and patriotism, about the need to preserve the self-consciousness of the people. Express your opinion by justifying your choice of position.

As the practice of using this textbook shows, the interest of students in the proposed topic within the framework of a specific text mobilizes their attention and concentration, contributes to a better assimilation of educational material. The communicative potential of the text largely depends on the perception of the reader, his intellectual level, belonging to a certain linguocultural community. One and the same text can be communicative for one audience and is not communicative for another audience. Therefore, when selecting texts for the textbook under consideration, both the internal (objective) communicativeness inherent in the texts and the external communicativeness determined on the basis of the possibility of their impact on the specific addressee (3rd-4th year students in the specialty "regional studies") were taken into account.

Another important criterion for selecting the texts of the textbook under consideration was the language. The lexical and grammatical material was selected taking into account the set educational and methodological tasks in accordance with the approved curriculum of the aforementioned specialty. 
In the course of work on the textbook in general and the process of selecting text material in particular, certain features of a linguoculturological nature were identified. So, the texts are light in their linguistic and content parameters, in a number of cases they turned out to be difficult enough to assimilate from the point of view of national specifics.

When selecting texts, the language perceptions of the target audience were also taken into account: Russian-speaking students of a language university who have verbal experience of communication not only in their native language, but also in a foreign one, which made the influence of the associations of the native language quite noticeable when assimilating the foreign (Kyrgyz) language.

Such associations are due to both the actual linguistic connections of words, showing the most familiar for native speakers, stable phrases, idioms, clichés and reflecting the characteristics of the culture of one or another people, and semantic connections. For example, one of the tasks of the textbook is formulated as follows: "Read the following aphorisms reflecting folk wisdom. Find concepts that are typical for both Kyrgyz and Russian cultures. Compare their semantic content. Does it always match? Justify your opinion and give specific examples. "

Thus, when selecting texts for a textbook, it is extremely important to take into account the entire complex of criteria: linguistic, content and communicative, including the associative socioculturally conditioned connections that arise in the process of assimilating the text.

It is this approach that provides the most adequate selection of textual material as: relevant, universal, informative, accessible, as well as containing elements with ethnocultural specificity, forming the conceptual sphere of the Kyrgyz linguistic personality and giving an idea of the linguistic picture of the world of the Kyrgyz linguistic personality.
[1] Bakieva G. X., Karaeva B. X., Korshunova E. N., Kraeva I. A, Teshabaeva D. M., Frolova G. M. Uzbek language for SNG page. - M .: FGBOU VPO MGLU, 2012 - 331s.

[2] Bredixina I. A. Method of preparation of foreign languages. Training is based on rechevoy deyatelnosti. Uchebnoe posobie. - Ekaterinburg: 2018 - 108 p.

[3] Kuznetsov I.N. Modern business rhetoric. -M .: Gross Media 2007 - 320 p.

[4] Lapidus B.A. Training in the second foreign language as a specialty. -M., Vysshayaola.1980 - 172s.

[5] Rabochaya programa distsipliny, B1.O.19.03 Inostrannyy yazyk (vtoroy) uzbekskiy, 41.03.01 - Zarubejnoe regionovedenie) napravlennnost (rofil, spetsializatsiya) obrazovatelnoy programmy: Mezhdunarono-politicheskiy analiz regionov mira. -M .: 2019 - 51s.

[6] Raxmanov I.V. Obuchenie ustnoy rechi na inostrannom yazyke.Uchebnoe posobie. M .: $1980-119$ p.

[7] Arutyunov R.A. Theory and practice of creating a textbook of the Russian language for foreigners. - Moscow, Russian language, 1990 .-- 167 p.

[8] Baiterekova Zh.S. and other Kyrgyz language for the CIS countries. Textbook. - Moscow, IP "Rema", 2012. - 468 p.

[9] Bakhtin M.M. Aesthetics of verbal creativity. - Moscow, Art, 1986 .-- 445 p.

[10] Glukhov A.G., Shchukin A.N. Terms of methods of teaching Russian as a foreign language. - M .: Russian language, 1993 .- 369 p.

[11] Kulibina N.V. Why, what and how to read in the lesson: a methodological guide. SPb.: Zlatoust, 2015 .-- 224 p.

[12] Safaryan R.D. Theoretical foundations of a textbook of Russian literature for Armenian students at an advanced stage of education. Diss. d.p.n. - Moscow, 2004 .-- 446 p.

\section{References}

